\title{
Anti-inflammatory Effects of a Small Molecule Gastrin-Releasing Peptide Receptor Antagonist on Adjuvant-Induced Rheumatoid Arthritis in Rats
}

\author{
Wen-yi Mei, ${ }^{a, \#}$ Ming-jun Yu, ${ }^{a, \#}$ Sen Yao, ${ }^{a}$ Kui-ling Wang, ${ }^{b}$ and Ri-sheng Yao*,a,c \\ ${ }^{a}$ School of Biological and Medical Engineering, Hefei University of Technology; Hefei 230009, China: ${ }^{b}$ School of \\ Pharmacy, Anhui University of Chinese Medicine; Hefei 230012, China: and ${ }^{c}$ Engineering Research Center of Bio- \\ process, Ministry of Education, PRC, Hefei University of Technology; Hefei 230009, China. \\ Received November 5, 2017; accepted January 30, 2018; advance publication released online February 8, 2018
}

The anti-inflammatory effects of $(R)-2-(1 H$-Imidazol-1-yl) ethyl-3-(1H-indol-3-yl)-2-(2-p-tolylacetamido)propanamide (RH-1402), a previous designed small molecule Gastrin releasing peptide (GRP) antagonist were evaluated in adjuvant-induced arthritic model of rats, and the inhibitory effect on neutrophil migration induced by GRP was determined by a transwell system experiment in vitro. The arthritis was induced by injection of Complete Freund's Adjuvant (CFA) containing $10 \mathrm{mg} / \mathrm{mL}$ of heat killed mycobacterium into the left hind footpad. Experimental rats were randomly divided into 6 groups, including control, placebo, positive control group, RH-1402 of low/middle/high dose group. Disease incidence and severity was evaluated through scoring of the paw edema and histologic features of joint synovial. Blood of all experimental rats was collected for interleukin $1 \beta$ (IL-1 $\beta$ ) and tumor necrosis factor $\alpha$ (TNF- $\alpha$ ) cytokine levels. A transwell system was used to investigate whether RH-1402 would inhibit neutrophils migrating up a gradient of GRP in vitro. RH-1402 (5 and $10 \mathrm{mg} / \mathrm{kg}$ ) significantly decreased adjuvant induced increased arthritis index during the administration period (days 14-20). Significant inhibition of joint synovial histological features can be found in the RH-1402 treated group, including alleviated Hyperplasia, Inflammatory of infiltration and activation of pannus formation. It also suppressed TNF- $\alpha$ and IL-1 $\beta$ level. Five and $10 \mathrm{mg} / \mathrm{kg}$ of RH-1402 significantly inhibited the effect of GRP on neutrophil migration with a dose dependent relationship. These findings indicate that RH-1402 have potential protective anti-inflammatory effects on experimental models of arthritis.

Key words rheumatoid arthritis; gastrin releasing peptide receptor; anti-inflammatory

Rheumatoid arthritis (RA), as a common progressive, autoimmune disease, affects up to $1 \%$ of people worldwide. ${ }^{1)}$ Synovial hyperplasia with inflammatory cell infiltration, pannus formation and destruction of bone and cartilage can be observed in pathologic processes of RA. ${ }^{1,2}$ Common symptoms of RA, including swollen, pain and stiffness of joints, bring physical discomfort, difficulty moving and even disabling. ${ }^{3)}$ RA has complex causing and multiple pathogenic mechanism, and its exact pathogenesis is still obscure. ${ }^{4)}$ Although currently available chemotherapeutic drugs, including cyclooxygenase inhibitors like celecoxib and a variety of disease modifying anti-rheumatic drugs (DMARDs) like methotrexate, can reduce and/or delay the pathological process of a subset of patients, there are fair number of patients with an inadequate response to these conventional drugs, and it is wildly considered that treatment results of these drugs are not very satisfactory. Increasingly attention has been paid to biological therapy. However, the high cost, inconvenient administration and potentially serious side effects prevent it from being widely used. ${ }^{5)}$ In consideration of the limitations of current drug treatments, novel therapeutic targets in rheumatoid arthritis are important to address clinical needs.

Gastrin-releasing peptide (GRP) is the mammalian homologue of bombesin (BN). GRP affects several systems in mammals, including neuroendocrine regulation, gastrointestinal secretion and cell proliferation. ${ }^{6-9)}$ More recently, it has been reported that releasing of GRP closely related to the

\footnotetext{
\# These authors contributed equally to this work.

progression and severity of chronic inflammatory diseases, including RA, and administration of GRP receptor (GRPR) antagonist have anti-inflammatory effects in inflammation models. ${ }^{7,10-12)}$ RC-3095 is a synthetic polypeptide BN/GRP antagonist with the molecular weight (MW) of 1106.32. Studies showed that RC-3095 could be an attractive and safe candidate compound for future trials in GRPR-related diseases, including specific types of cancer and chronic inflammatory diseases. ${ }^{7,10,13,14)}$ Administration of RC-3095 suppressed the growth of CFPAC-1 human pancreatic cancers and MDA-MB-435 breast cancers in nude mice, and the protein levels of basic fibroblast growth factor (bFGF), insulin-like growth factors (IGF-II) and vascular endothelial growth factor (VEGF) in the tumors largely reduced. ${ }^{13,14)}$ Previous researches also showed that RC-3095 have protective effects in experimental RA models of collagen-induced arthritis (CIA) and antigen-induced arthritis (AIA), and it was associated with a substantial reduction in levels of pro-inflammatory cytokines, such as tumor necrosis factor $\alpha(\mathrm{TNF}-\alpha)$ and interleukin $1 \beta$ (IL- $1 \beta))^{7,10)} \mathrm{As}$ a polypeptide, RC-3095 is difficult to synthesize and use, there may be a limitation of its application.

Thus, in the present study, we studied the anti-inflammatory effects of RH-1402 on rats with adjuvant-induced arthritis.

\section{Experimental}

Drugs, Chemicals and Reagent Kits GRPR antagonist RH-1402 was self synthesized. Complete Freund's Adjuvant (CFA) was purchased from Chondrex, Inc. (Redmond, U.S.A.); Methotrexate (MTX) was purchased from Pude Pharmaceu- 
tical Co. (Shanxi, China); Transwell system was purchased from Corning, Inc. (NY, U.S.A.); All enzyme-linked immunosorbent assay (ELISA) kits were purchased from Elabscience Biotechnology Co. (Wuhan, China).

Animals Sprague-Dawley (SD) rats weighing 190-240g were obtained from the Animal Center of Anhui Medical University (Hefei, China). The animals were caged at room temperature, with $12 \mathrm{~h}$ light: $12 \mathrm{~h}$ dark cycle and free access to food and water until the time of experiments. (Ethnic audit). Experimental rats were randomly divided into 6 groups, with 8 subjects in each group: (1) Control (not manipulated); (2) Placebo (intraperitoneal (i.p.) injection of the solvent of tested compound $10 \mathrm{~mL} / \mathrm{kg}$, once a day for $7 \mathrm{~d}$ starting after 14th day of CFA induction); (3) Positive control group (per os (p.o.) administration of $1 \mathrm{mg} / \mathrm{kg}$ of MTX once a day for $7 \mathrm{~d}$ starting after 14th day of CFA induction); (4) Low dose group (i.p. injection of $2.5 \mathrm{mg} / \mathrm{kg}$ of $\mathrm{RH}-1402$ once a day for $7 \mathrm{~d}$ starting after 14th day of CFA induction); (5) Middle does group (i.p. injection of $5 \mathrm{mg} / \mathrm{kg}$ of $\mathrm{RH}-1402$ once a day for $7 \mathrm{~d}$ starting after 14th day of CFA induction); (6) High does group (i.p. injection of $10 \mathrm{mg} / \mathrm{kg}$ of $\mathrm{RH}-1402$ once a day for $7 \mathrm{~d}$. The animals were monitored for $28 \mathrm{~d}$ and sacrificed on the $28 \mathrm{th}$ day after modeling. Blood was collected by abdominal aortic method to determine serum cytokine levels, and joint synovials were collected for histology analysis. All animal care and experimental procedures were carried out in accordance with the Ethical Regulations for the Care and Use of Laboratory Animals of Anhui Medical University. All efforts were made to minimize the suffering.

Induction of Adjuvant Arthritis (AA) Rats were immunized on day 0 by intradermal injection of a $0.1 \mathrm{~mL}$ aliquot of CFA containing $10 \mathrm{mg} / \mathrm{mL}$ of heat killed mycobacterium of paraffin oil into the left hind paw. ${ }^{15)}$ Arthritis was characterized by the first signs of redness or swelling of the ankle joints, which was observed at 10-12 d after the immunization.

Arthritis Scoring A standardized method of arthritis scoring was used to evaluate the degree of swelling and erythema of the paws: $0=$ normal, $1=$ mild swelling and erythema, $2=$ moderate swelling and erythema, $3=$ severe swelling and erythema plus loss of function in 2 paws, and $4=$ total loss of function in a minimum of 3 paws. ${ }^{11)}$ The arthritis scoring was evaluated blindly every three days $(0 \mathrm{~d}, 3 \mathrm{~d} . .21 \mathrm{~d})$ from modeling day to $28 \mathrm{~d}$ after modeling.

Histology and Histologic Scoring On the day 28, all the rats were sacrificed, joint synovium was removed from knee joints. All synovium fixed in $4 \%$ buffered paraformaldehyde, embedded in paraffin, sectioned at $5 \mu \mathrm{m}$ and stained with hematoxylin and eosin (HE) for histopathology analysis. Histologic scoring was carried out according to method built by Krenn et al. ${ }^{16)}$ Briefly, histologic scoring of synovial joint was divided into three specific parts: Hyperplasia/enlargement of synovial lining cell layer, inflammatory of infiltration and activation of synovial stroma/pannus formation, and each part is classified into four grades (0-3) according to its severity, the maximum possible score for grading is 9 .

Assessment for Serum Cytokines The concentrations of IL-1 $\beta$, TNF- $\alpha$ were evaluated by enzyme linked immuno sorbent assay following the instructions of manufacturer.

Determination of the Inhibitory Effect on Neutrophil Migration Induced by GRP in Vitro A transwell system was used to investigate whether RH-1402 would inhibit neu-

trophils to migrate up a gradient of GRP in vitro. Heparin treated peripheral venous blood of healthy human volunteers was used to isolate human neutrophils. The inhibiting effect was evaluated using a previously described method, ${ }^{17)}$ briefly, the used transwell system contains a top well and a bottom, and they are partitioned off with a $5 \mu \mathrm{m}$ polycarbonate membrane. $1 \mathrm{~nm}$ GRP was added to the bottom wells as chemotaxis in RPMI 1640 medium with $2 \%$ fetal calf serum (FCS). Neutrophils $\left(2 \times 10^{5} \quad\right.$ cells $\left./ 100 \mu \mathrm{L}\right)$ suspended with/without RH-1402 (1, 10, 20nm, respectively) were added to top wells in the same medium and incubated for $2 \mathrm{~h}$ at $37^{\circ} \mathrm{C}$ under $5 \%$ $\mathrm{CO}_{2}$ atmosphere. After incubation, the migrated neutrophils were collected and counted in Neubauer chambers. Neutrophil migration toward RPMI medium 1640 alone (random chemotaxis) was used as negative control.

Determination of the Inhibitory Effect on Neutrophil Migration Induced by GRP in Vivo The mice were injected with $0.6 \mu \mathrm{g}$ GRP and/or RH-1402 (3, 6, $12 \mu \mathrm{g}$, respectively) $\mu \mathrm{g}$ in the appropriate solvent, and the blank group was injected with saline. The number of neutrophils and the total number of white blood cells were examined by flow cytometry with $3 \mathrm{~mL}$ of cold phosphate buffered saline (PBS) solution after $4 \mathrm{~h}$.

Immunohistochemical Analysis for GRPR Rat synovial joints were fixed with ice-acetone for $15 \mathrm{~min}$, and permeabilized with $0.3 \%$ Triton X-100 in PBS for $15 \mathrm{~min}$. The cells were performed as performed as previously described. ${ }^{18)}$ Cells were wished and imaged under an inverted fluorescence microscope (Olympus).

Statistical Analysis Results are expressed as mean \pm standard error of the mean (S.E.M.), the data obtained was analyzed by Student $t$-test, significance was accepted at $p<0.05$ levels. All statistical analyses were performed using the statistical package SPSS 21 for Windows (SPSS, Inc., Chicago, IL, U.S.A.).

\section{Results}

Arthritis Score After 14d of CFA-induction, all animals' injected paws and more than $75 \%$ contralateral paws had developed a severe arthritis excepted vehicle injected control groups. The foot claw showed obvious swelling in AA rats compared with normal rats (Fig. 1). Generally, administration of 5 and $10 \mathrm{mg} / \mathrm{kg} \mathrm{RH}-1402$ relieve extent of edema and red of rats' paws, and showed significant difference in the arthritis score with negative control group, however, this effect only can be found during the administration period (days 14-20,

AA

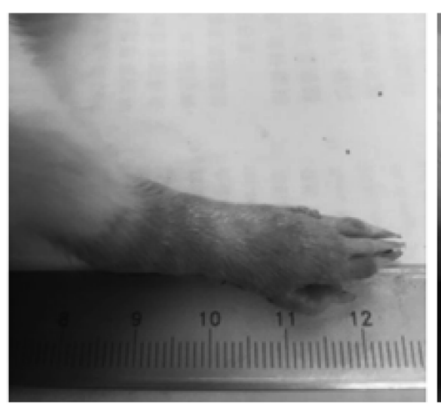

Fig. 1. Representative Image of Paw Edema in Rats with CFA-Induced Arthritis (CIA) 
Fig. 2). There was no significant difference in the arthritis score between the all treated groups (RH-1402 and MTX) and negative control after administration period (days 21-28).

Histology and Histologic Scoring Not-manipulated group presented normal synovial tissues, while negative

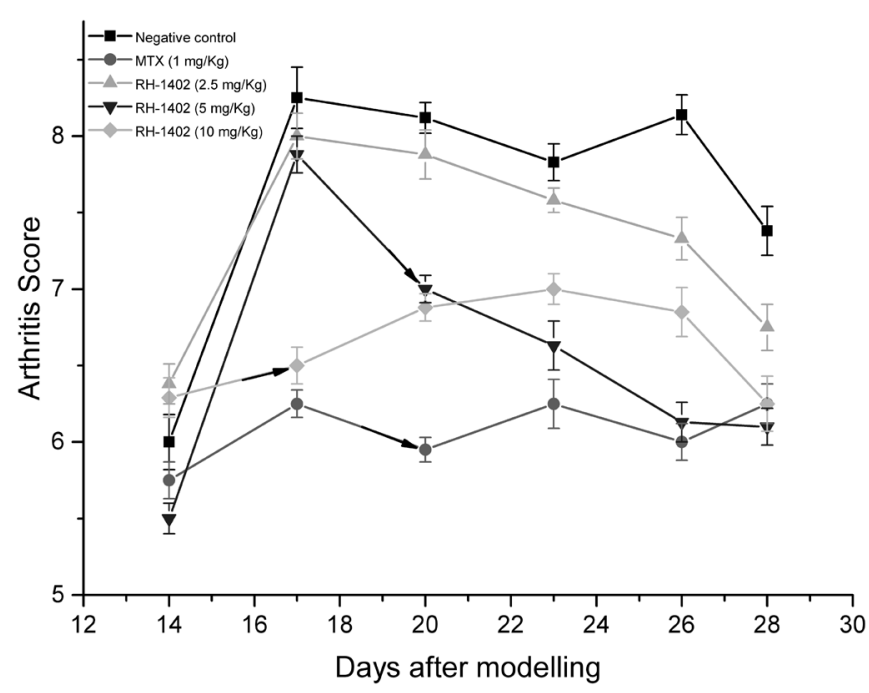

Fig. 2. Arthritis Score in Animals with CFA-Induced Arthritis (CIA)

Black arrow before data points means $p<0.05$ versus treated groups and negative control. Results were the mean of 8 mice per group. control group presented very abnormal histology of the joint synovium, including severe enlargement of synovial lining cell layer, strong inflammatory infiltration and pronounced pannus formation (Figs. 3A, B). MTX and RH-1402 with all dose levels treated group could improve synovial histologic characteristics at some extent, synovitis score (total score of 3 partial fraction) showed significant difference with the negative group, but there was no statistical difference in synovitis score among all treated group (Table 1 and Figs. 3C-F). Although similar synovitis score was showed between MTX and RH-1402 treated groups, performance on 3 specific parts of histologic features was different.

Cytokine Serum Levels Two main pro-inflammatory cytokines, IL- $1 \beta$ and TNF- $\alpha$, in serum were evaluated by ELISA. Rats subjected to CFA presented a significant increase in serum IL- $1 \beta$ and TNF- $\alpha$ level when compared with normal rats. All cytokine levels were decreased in the RH-1402 treatment group, in relation with the degree of amelioration of the inflammatory reaction as measure with the parameters utilized in this study (Table 2).

Inhibitory Effect on Neutrophil Migration Induced by GRP in Vitro and in Vivo We found that $1 \mathrm{~nm}$ GRP could induce neutrophils to migrate up a gradient of GRP in the transwell system which is agreed with previous study. ${ }^{17)}$ Ten and $20 \mathrm{~nm}$ of RH-1402 significantly inhibited the effect of GRP on neutrophil migration with a dose dependent relationship (Fig. 4). In mice, 3, 6, and $9 \mu$ g of RH-1402 also inhibited
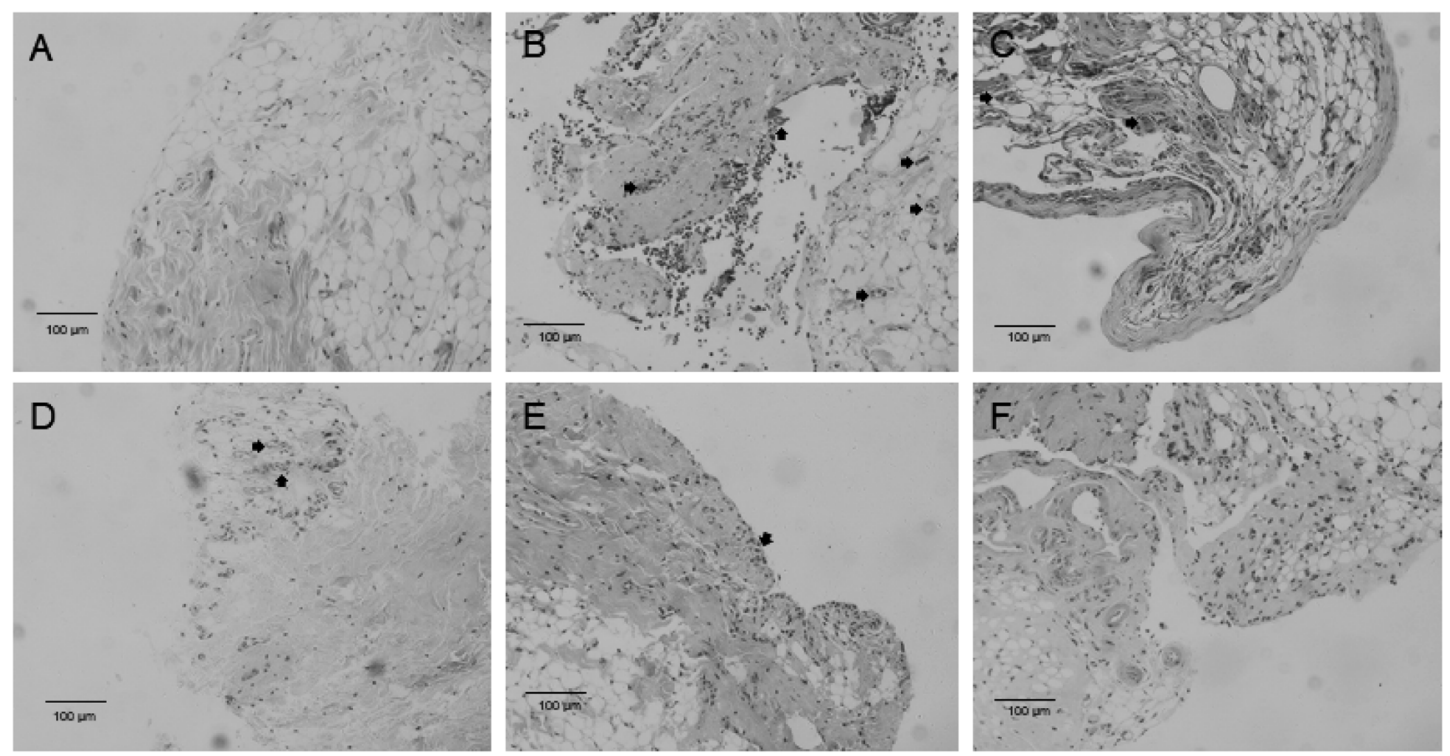

Fig. 3. Synovial Histologic Characteristics

A: Control (not manipulated), normal synovial tissues; B: Negative control group, very abnormal histology of the joint synovium with severe enlargement of synovial lining cell layer, strong inflammatory infiltration and pronounced pannus formation; C: MTX treated group; D, E and F: $2.5,5,10 \mathrm{mg} / \mathrm{kg}$ RH-1402 treated group, all treated groups showed decreased synovial inflammation; Arrows indicate, Inflammatory infiltration, and the arrows heads, indicate pannus formation. Stained with hematoxylin and eosin. Original magnification $\times 100$.

Table 1. Histology and Histologic Scoring of Synovial Tissues of Rats with CFA-Induced Arthritis Treated with RH-1402

\begin{tabular}{|c|c|c|c|c|c|c|}
\hline & Blank & Negative control & MTX (1 mg/kg) & RH-1402 (2.5 mg/kg) & RH-1402 (5 mg/kg) & RH-1402 (10 mg/kg) \\
\hline Hyperplasia & $0.0 \pm 0.0$ & $3.3 \pm 0.6$ & $2.0 \pm 1.0$ & $1.6 \pm 0.3 *$ & $2.0 \pm 0.6$ & $1.3 \pm 0.6^{*}$ \\
\hline Inflammatory infiltration & $0.0 \pm 0.0$ & $2.7 \pm 0.3$ & $1.0 \pm 0.0$ & $2.0 \pm 0.0$ & $2.0 \pm 0.4$ & $1.3 \pm 0.3^{*}$ \\
\hline Pannus formation & $0.0 \pm 0.0$ & $2.0 \pm 0.0$ & $1.7 \pm 0.3$ & $1.7 \pm 0.3$ & $1.25 \pm 0.3$ & $1.3 \pm 0.3$ \\
\hline Synovitis score & $0.0 \pm 0.0$ & $8.0 \pm 0.6$ & $4.7 \pm 0.7 *$ & $5.3 \pm 0.3 *$ & $5.3 \pm 0.8^{*}$ & $4.0 \pm 1.0^{*}$ \\
\hline
\end{tabular}

Values are mean \pm S.E.M., $n=8$ (Blank, negative control, MTX and RH-1402 groups, respectively). $* p<0.05$ versus negative control and all treated groups 
Table 2. Effects of RH-1402 on the Serum Concentration of IL- $1 \beta$ and TNF- $\alpha$ in Rats with CFA-Induced Arthritis

\begin{tabular}{|c|c|c|c|c|c|c|}
\hline & Blank & Negative control & MTX (1 mg/kg) & RH-1402 (2.5 mg/kg) & RH-1402 (5 mg/kg) & RH-1402 (10 mg/kg) \\
\hline IL- $1 \beta$ & $60.5 \pm 9.7$ & $297.6 \pm 8.1^{\#}$ & $235.3 \pm 17.9 *$ & $187.4 \pm 40.5^{*}$ & $142.4 \pm 36.0 *$ & $120.9 \pm 30.4^{*}$ \\
\hline TNF- $\alpha$ & $49.4 \pm 10.0$ & $297.6 \pm 18.3^{\#}$ & $53.0 \pm 0.9 *$ & $49.9 \pm 22.7^{*}$ & $64.4 \pm 26.9 *$ & $114.6 \pm 15.3 *$ \\
\hline
\end{tabular}

Values are mean \pm S.E.M., $n=8$ (Blank, Negative control, MTX and RH-1402 groups, respectively). ${ }^{*} p<0.05$ versus blank and negative control; ${ }^{*} p<0.05$ versus negative control and all treated groups.

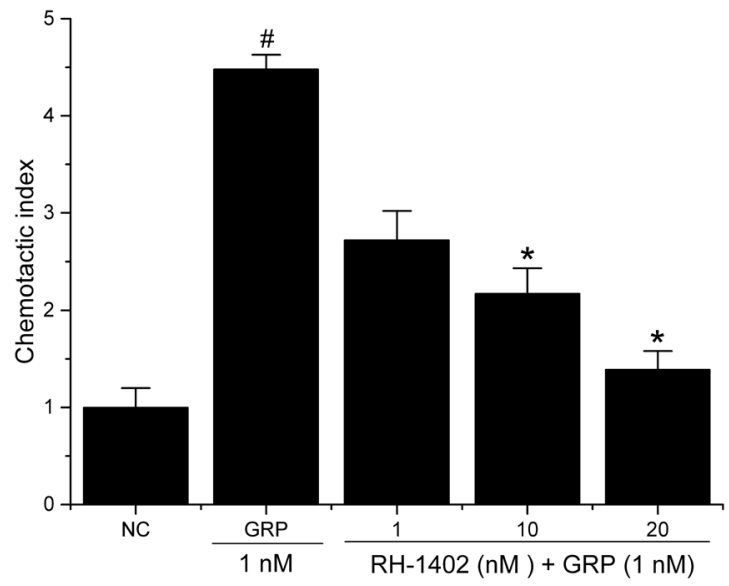

Fig. 4. Value Are Mean \pm S.E.M.; The Chemotactic Index Was Obtained as the Ratio of the Number of Migrated Neutrophils in GRP-Containing Wells Divided by the Number of Neutrophils That Migrated to the Medium Alone, the Data Were Representative of at Least 3 Independent Experiments

${ }^{\#} p<0.05$ versus blank and negative control; ${ }^{*} p<0.05$ versus negative control and all treated groups.

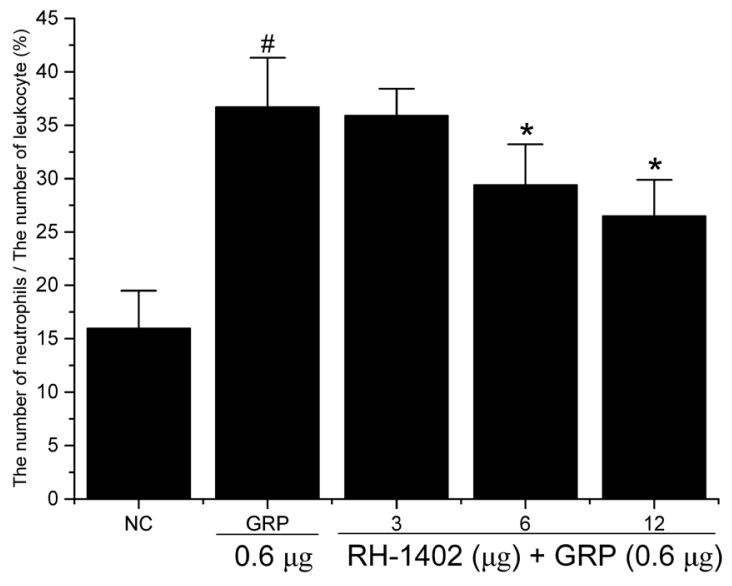

Fig. 5. Value Are Mean士S.E.M.; Determination of the Inhibitory Effect on Neutrophil Migration Induced by GRP in Vivo

Data are expressed as the mean \pm S.E.M., $n=4$ (negative control, GRP and RH-1402 groups, respectively). ${ }^{\#} p<0.05$ versus blank and negative control. $* p<0.05$ versus negative control and all treated groups.
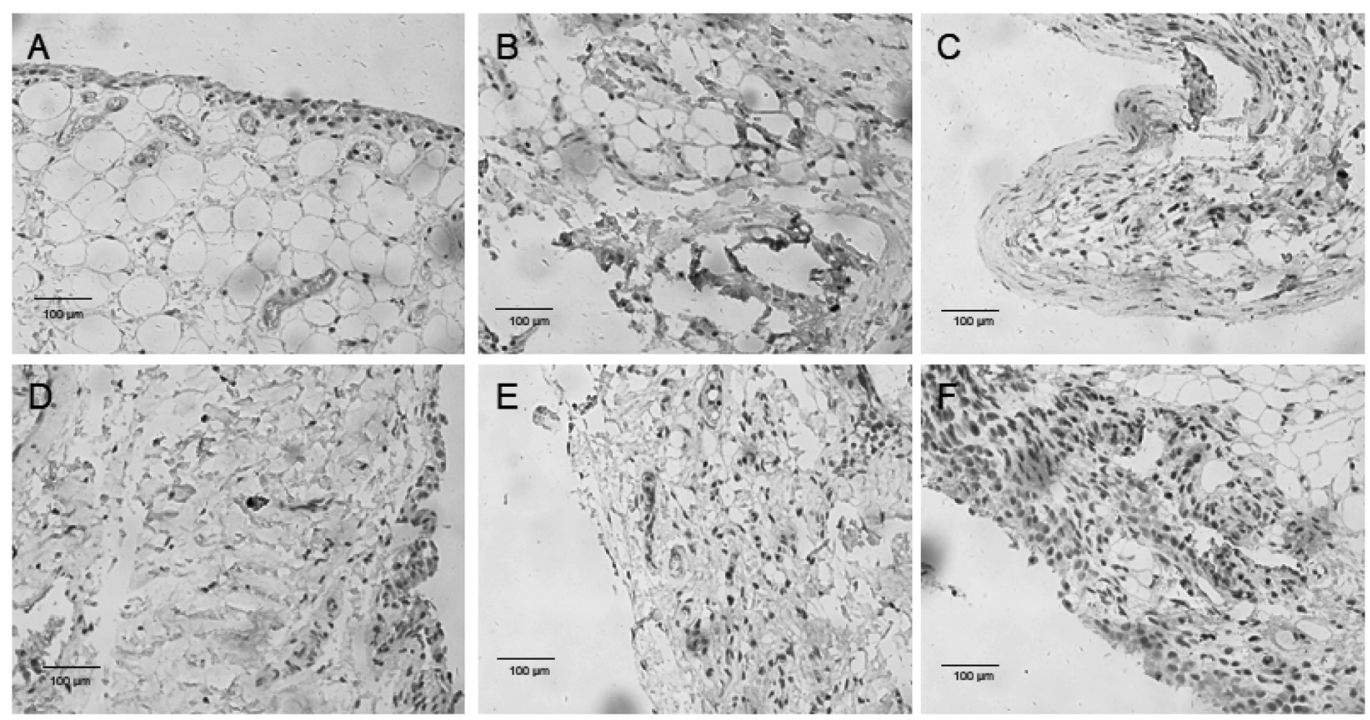

Fig. 6. Evaluation of GRPR Expression in the Synovial Joints of Rats with CFA-Induced Arthritis (CIA)

A: Control (not manipulated), normal synovial tissues; B: Negative control group; C: MTX treated group; D, E and F: 2.5, 5, 10 mg/kg RH-1402 treated group, original magnification $\times 100$.

neutrophil migration (Fig. 5).

Effect of Treatment with RH-1402 on GRPR Expression Immunohistochemical analysis for GRPR was performed in the synovial joints of rats with CFA-induced arthritis (Fig. 6). The GRP receptor was stained and detected in the cell membrane and cytoplasm.

\section{Discussion}

In RA, immune cells, including activated B and $\mathrm{T}$ cells, plasma cells, macrophages and neutrophils, combined with activated resident tissue cells infiltrate the synovial membrane, destroy bone and cartilage destruction and take part in an aggravating inflammatory process. ${ }^{3)}$ Although its etiology still remains largely unclear, many studies show that during the disease course, the synovial membrane is infiltrated by 
CD4+ T-lymphocytes via autoimmune mechanism, then B cell and other immune cells like macrophages are stimulated and aggregated to produce rheumatoid factor (RF), cytokines, particularly interleukins (ILs) and TNF- $\alpha$, and other related enzymes, which play a critical role in mediating processes of inflammatory reaction. ${ }^{19)}$ Anti-inflammatory and immunosuppressive agents, like dexamethasone and methotrexate are the mainstay of treatment for RA, however, because of various adverse effects of them, they are unsatisfied in majority of patients. $^{20)}$ More recently, biological therapy like anti- tumor necrosis factor (TNF) treatment offers real benefit to many patients with severe RA, but obviously, targeting a single cytokine is not enough for all subpopulation of RA patients. Therefore, searching new targets for pharmacological designing and alternative approaches for RA treatment is necessary. Targeting neuropeptides might be a promising method for RA treatment. Previous works showed that increased levels of the peptide can be found in synovial fluid of RA patients, ${ }^{21)}$ and immunoreactions for GRPR can also be observed in cells in the inflammatory infiltrates of AIA mice. ${ }^{22)}$ However, the levels of reactions for GRPR in the CFA induced mice were variable, immunoreactions for GRPR of animals with severely arthritic joints were significantly lower than that of control. In present work, the expression of GRPR in joint synovial and cartilage was assayed by immunohistochemical staining, we also observed the similar phenomenon. A potential reason is that elevated peptide producing in synovial fluid attribute to the decreased peptide receptor by compensatory mechanisms. GRP/GRPR may enhance the expression of cyclooxygenase-2 (COX-2) and VEGF, which are closely related to syndromes of RA and pannus formation. ${ }^{23)}$ Expression of GRP has been found in immune cells, and using GPRP antagonist would reduce the release of some pro-inflammatory cytokines (TNF- $\alpha$ and IL-1 $\beta$ ) by lipopolysaccharide (LPS) activated macrophages, while the release of anti-inflammatory cytokine, interleukin-10, are not affected. ${ }^{24)}$ Adjuvant-induced arthritis (AIA) was used as model for evaluation, because it is a well established model for experimental rheumatoid arthritis, which has many similar features with RA of human, like genetic linkage, synovial CD4+ cells and $\mathrm{T}$ cell dependence. ${ }^{25,26)}$

In present study, the significant difference in arthritis score between treated groups and negative control can only be seen within the administration period (days 14-20). After administration period (days 21-28) arthritis score of middle and high dosage of RH-1402 are generally lower than that of negative control. Previous researches showed that extensive periarticular soft tissue edema and histological panniculitis caused among the CFA-injected animals, and $0.3 \mathrm{mg} / \mathrm{kg}$ of RC-3095 cannot reverse these symptoms, although it significant inhibited the release of inflammatory cytokine. ${ }^{7,12}$ Alternatively, although the metabolic characteristics of RH-1402 need to be further investigated, we speculate on that, after administration period, the real compound concentration would not be so relevant for reversing the continuing process of histological panniculitis because of drug metabolism.

Joint synovium was removed and evaluated for histologic examination. An research indicated that an increase in GRPR expression could be found in the synovial cells of arthritis model mice, but that in cartilage was variable. ${ }^{7}$ Grimsholm et al. showed a similar phenomenon, and found that abundant GRP immunoreactive fibers with a varicose appearance in as- sociation with the inflammatory infiltrates. ${ }^{22)}$ The histopathological grading method for chronic synovitis we used was created by Krenn et al. in 2002, through their validation, it showed that basic and standardized information in association with the level of inflammatory alterations in synovial tissue could be provided by using this grading system. ${ }^{16)}$ In present work, with treatment of RH-1402, when compared with negative controls, relatively thinner the synovial lining layer presented, reduction of giant cells and lymphocytes were found in the enlarged synovial lining, aggregates of lymphocytes can be detected in the perivascular region, and they were mostly in a concentric arrangement, but the total amount of the cells was significantly lower than that of negative controls, in 5 and $10 \mathrm{mg} / \mathrm{kg} \mathrm{RH}-1402$ groups, pannus formation was greatly reduced as compared to negative controls.

Inflammation and subsequent tissue damage may result from an imbalance in the cytokine network, excessive secretion of pro-inflammatory cytokines may promote autoimmunity. IL- $1 \beta$ and TNF- $\alpha$ are the most important, primary cytokines, which are closely related to activation of $\mathrm{T}$ cells and induce expression of other pro-inflammatory proteins. ${ }^{3)}$ TNF- $\alpha$ inhibitor, like infliximab and IL-1 inhibitor, like interleukin receptor blocker, are now effectively applied in the clinical treatment of RA. Previous works showed the elevated levels of IL- $1 \beta$ and TNF- $\alpha$ in different inflammation models, and they can be inhibited by administration of a GRPR antagonist, RC-3095., ${ }^{7,26)}$ Both serum IL-1 $\beta$ and TNF- $\alpha$ concentration were significantly inhibited by administration of all three dosages of RH-1402.

Neutrophils are the most abundant cell type in inflammatory site, which are capable of inducing inflammatory response and damage. ${ }^{27)}$ The recruitment of neutrophils leads to local production of cytokines, chemokines, prostaglandins, leukotrienes, granule proteins, and reactive oxygen species (ROS), promoting the aggregation and activation of antigen presenting cells, and sending signals to nearly all immune cells. ${ }^{28,29)}$ In RA, the infiltration of neutrophils is closely related to the aggravating of the clinical condition and symptoms, like cartilage and bone destruction and pain. ${ }^{30)}$ Interference of infiltration of neutrophils therefore is effective for the treatment of RA. Czepielewski showed that GRP is a chemoattractant for neutrophils through both directly and indirectly mechanism and chemotactic effect of GRP was restricted to GRPR binding. ${ }^{17)}$ A checkerboard analysis was also designed by their group, and proved that GRP has a chemotactic effect rather than simply a chemokinetic one. In our study, RH-1402 significantly inhibited the recruitment of neutrophils of human peripheral blood directly induced by GRP with a dose dependent manner in vitro.

In conclusion, RH-1402, as a small molecule GRP antagonist, has potential protective effect in experimental model of arthritis. These observations may provide reference for clinical treatment or new drug design strategy of RA. Further investigation of more comprehensive biological evaluation, tests with more abundant structure and structural modification are under developing.

Acknowledgments This work was supported by the National High Technology Research and Development Program of China (863 Program, No. 2014AA021902), the National Natural Science Founding of China (No. 31400049). 
Conflict of Interest The authors declare no conflict of interest.

\section{References}

1) Rossi D., Modena V., Sciascia S., Roccatello D., Int. Immunopharmacol., 27, 185-188 (2015).

2) Koenders M. I., Berg W. B., Trends Pharmacol. Sci., 36, 189-195 (2015).

3) Brzustewicz E., Bryl E., Cytokine, 76, 527-536 (2015).

4) Choy E., Rheumatology, 51 (Suppl. 5), 3-11 (2012).

5) Ho L. J., Lai J. H., Eur. J. Pharmacol., 747, 200-205 (2015).

6) Swain M. J., J. Hepatol., 48, 681-683 (2008).

7) Oliveira P. G., Brenol C. V., Edelweiss M. I., Brenol J. C. T., Petronilho F., Roesler R., Pizzol D., Schwartsmann G., Xavier R. M., Peptides, 29, 1726-1731 (2008).

8) Takanami K., Sakamoto K., Curr. Neuropharmacol., 12, 434-443 (2014).

9) Green P. G., Arthritis Res. Ther., 7, 111-113 (2005).

10) Oliveira P. G., Gerspan R., Pinto L. G., Meurer L., Brenol J. C. T., Roesler R., Schwartsmann G., Cunha F. Q., Xavier R. M., Arthritis Rheum., 63, 2956-2965 (2011).

11) Kagami S., Sugaya M., Suga H., Morimura S., Kai H., Ohmatsu H., Fujita H., Tsunemi Y., Sato S., J. Invest. Dermatol., 133, 1673-1675 (2013).

12) Dal-Pizzol F., Leone L. P. D., Ritter C., Martins M. R., Reinke A., Gelain D. P., Zanotto-Filho A., Souza L. F. D., Andrades M., Barbeiro D. F., Bernard E. A., Cammarota M., Bevilaqua L. R. M., Sorano F. G., Cláudio J., Moreira F., Roesler R., Schwartsmann G., Am. J. Respir. Crit. Care Med., 173, 84-90 (2006).

13) Qin Y. F., Ertl T., Cai R. Z., Halmos G., Schally A. V., Cancer Res., 54, 1035-1041 (1994).

14) Bajo A. M., Schally A. V., Groot K., Szepeshazi K., Br. J. Cancer, 90, 245-252 (2004).

15) Huang X. Y., Chen F. H., Li J., Xia L. J., Liu Y. J., Zhang X. M., Yuan F. L., Anat. Rec., 291, 1029-1037 (2008).
16) Krenn V., Morawietz L., Häupl T., Neidel J., Petersen I., König A., Pathol. Res. Pract., 198, 317-325 (2002).

17) Czepielewskia R. S., Portoa B. N., Rizzo L. B., Roesler R., Abujamra A. L., Pinto L. G., Schwartsmann G., Proc. Natl. Acad. Sci. U.S.A., 109, 547-552 (2012).

18) Zhou R. P., Wu X. S., Wang Z. S., Ge J. F., Chen F. H., Immunopharmacology, 29, 748-760 (2015).

19) Wahba M. G. F., Messiha B. A. S., Abo-Saif A. A., Eur. J. Pharmacol., 765, 307-315 (2015)

20) Lampropoulos C. E., Orfanos P., Bournia V. K., Karatsourakis T., Mavragani C., Pikazis D., Manoussakis M. N., Tzioufas A. G., Moutsopoulos H. M., Vlachoyiannopoulos P. A., Clin. Exp. Rheumatol., 33, 216-224 (2015).

21) Westermark T., Rantapää-Dahlqvist S., Wållberg-Jonsson S., Kjörell U., Forsgren S., Clin. Exp. Rheumatol., 19, 715-720 (2001).

22) Grimsholm O., Guo Y. Z., Ny T., Rantapää-Dahlqvist S., Forsgren S., Ann. N. Y. Acad. Sci., 1110, 525-538 (2007).

23) Baroni A., Perfetto B., Canozo N., Braca A., Farina E., Melito A., Maria S. D., Carteni M., Peptides, 29, 1157-1166 (2008).

24) Petronilho F., Danielski L. G., Roesler R., Schwartsmann G., DalPizzol F., Inflamm. Allergy Drug Targets, 12, 172-177 (2013).

25) Waksman B. H., Scand. J. Immunol., 56, 12-34 (2002).

26) Kannan K., Ortmann R. A., Kimpel D., Pathophysiology, 12, $167-$ 181 (2005).

27) Fernandez-Botran R., FASEB J., 5, 2567-2574 (1991).

28) Santos E. O. L., Kabeya L. M., Figueiredo-Rinhel A. S. G., Marchi L. F., Andrade M. F., Piatesi F., Paoliello-Paschoalate A. B., Azzolini A. E. C. S., Lucisano-Valim Y. M., Int. Immunopharmacol., 21, 102-111 (2014).

29) Rosas E. C., Correa L. B., Pádua T. A., Costa T. E. M. M., Mazzei J. L., Heringer A. P., Bizarro C. A., Kaplan M. A. C., Figueiredo M. R., Henriques M. A., J. Ethnopharmacol., 175, 490-498 (2015).

30) Fattori V., Amaralb F. A., Verri W. A. Jr., Pharmacol. Res., 112, 84-98 (2016). 